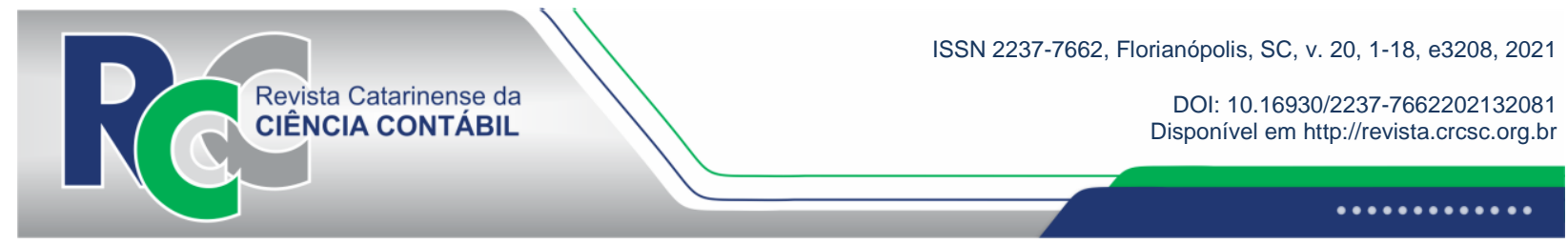

\title{
A CONTRIBUIÇÃO DOS PORTAIS ELETRÔNICOS ESTADUAIS PARA A TRANSPARÊNCIA DO PROCESSO DE VACINAÇÃO CONTRA A COVID-19 NO BRASIL
}

\section{THE CONTRIBUTION OF STATE WEB PORTALS TO THE TRANSPARENCY OF THE VACCINATION PROCESS AGAINST COVID-19 IN BRAZIL}

\author{
FABIANO MAURY RAUPP \\ Universidade do Estado de Santa Catarina. Endereço: Av. Madre \\ Benvenuta, 2037| Itacorubí| 88.035-001 | Florianópolis/SC | Brasil. \\ D http://orcid.org/0000-0001-9533-2574 \\ fabianoraupp@hotmail.com
}

\author{
ANA RITA SILVA SACRAMENTO \\ Universidade Federal da Bahia. Endereço: Av. Reitor Miguel Calmon, s/n \\ | Vale do Canela | 40.110-903 | Salvador/BA | Brasil. \\ (1) http://orcid.org/0000-0001-6739-5711 \\ anasacramento@ufba.br
}

\section{RESUMO}

O artigo objetivou caracterizar a contribuição dos portais eletrônicos dos estados brasileiros para a transparência do processo de vacinação contra a Covid-19. A pesquisa é do tipo descritiva, empreendida por meio de um estudo documental, com abordagem quali-quantitativa. O objeto de investigação compreende os portais eletrônicos dos 26 estados brasileiros e o Distrito Federal. O estudo guiou-se pela aplicação do Índice de Transparência da Vacinação contra a Covid-19 (ITVC19). Os dados da pesquisa foram obtidos em seis levantamentos realizados a partir de análise nos portais, tendo como técnica de tratamento a análise de conteúdo. Observou-se a constância de alguns estados em níveis superiores e inferiores (ou seja, nos extremos), e evolução de outros, saindo de níveis inferiores para níveis superiores. Embora a grande maioria dos portais eletrônicos dos estados brasileiros contribuam para a transparência da vacinação contra a Covid-19, ainda há estados cujo portais, por se situarem em níveis opaco, baixo e médio, parecem existir mais em razão de um imperativo tecnológico dominante e menos para favorecer a transparência das ações governamentais. Tem o estudo uma implicação teórica direta quando proporciona o desenvolvimento de um índice que contribui para a análise da transparência no processo de vacinação contra a Covid-19. Pressupõe-se que o índice, futuramente, poderá ser utilizado também para novos estudos sobre campanhas de vacinação, e não apenas este restrito ao contexto pandêmico. Consequentemente contribui com o gap na literatura, notadamente nacional. A

\footnotetext{
Editado em português e inglês. Versão original em português.
}

Recebido em 18/9/2021. Revisado em 18/10/2021. Aceito em 29/10/2021 pelos Prof. Dr. Sérgio Murilo Petri (Editor-Chefe) e Prof. Dr. Sandro Vieira Soares (Editor Adjunto). Publicado em 19/11/2021.

Copyright ( 2021 RCCC. Todos os direitos reservados. É permitida a citação de parte de artigos sem autorização prévia, desde que identificada a fonte. 
contribuição prática também é demonstrada pelo fornecimento de um diagnóstico que, embora pontual, poderá ser utilizado pelos gestores públicos interessados em fazer avançar a transparência da vacinação.

Palavras-chave: Transparência. Vacinação. Covid-19.

\begin{abstract}
The article aimed to characterize the contribution of Brazilian state web portals to the transparency of the vaccination process against COVID-19. This research is descriptive, undertaken through a documentary study with a quali-quantitative approach. The purpose of the investigation comprises the web portals of the 26 Brazilian states and the Federal District. The study was guided by the application of the COVID-19 Vaccination Transparency Index (ITVC19). The study data were obtained in six surveys carried out from the analysis of the portals, using content analysis as the processing technique. The constancy of some states at higher and lower levels (i.e., the extremes) and the evolution of others going from lower to higher levels was observed. Although the vast majority of web portals of Brazilian states contribute to the transparency of the vaccination against COVID-19, there are still states the portal of which, for being at opaque, low, or intermediary levels, seem to exist more due to a dominant technological imperative and less to favor the transparency of government actions. The study has a direct theoretical implication when it enables the development of an index that contributes to analyzing the transparency in the vaccination process against COVID-19. It is assumed that, in the future, the index may also be used for new studies on vaccination campaigns, not just this one restricted to the pandemic context. Consequently, it contributes to bridging the gap in the literature, notably the national literature. The practical contribution is also demonstrated by the provision of a diagnosis that, albeit specific, may be used by public managers interested in advancing vaccination transparency.
\end{abstract}

Keywords: Transparency. Vaccination. COVID-19.

\title{
1 INTRODUÇÃO
}

Um dos lócus escolhido com frequência por pesquisadores interessados em avaliar a transparência no Brasil tem sido os portais eletrônicos (Michener, Contreras, \& Niskier, 2018), integrantes das modernas tecnologias de informação e comunicação e capazes de contribuir para a efetivação da transparência, e consequentemente da própria accountability. A construção de instrumentos de transparência como os portais "é um processo político que se efetiva no contexto da democratização do país e da necessidade de legitimação política dos governantes" (Loureiro, Teixeira, \& Prado, 2008, p. 108). Embora haja regulamentação para a obrigatoriedade do uso de portais neste sentido, pressupõe-se que a transparência extrapola as exigências legais e deve ser apropriada em uma sociedade enquanto valor fundamental (Raupp \& Pinho, 2021).

Para Raupp, Sacramento, Santos e Pinho (2021), com a emergência da pandemia da Covid19 e a consequente aprovação pelas agências de vigilância de vacinas para aplicação em caráter emergencial, a transparência tornou-se condição para evitar que práticas do tipo desvios, corrupção e clientelismo apareçam em países que, como o Brasil, enfrentam problemas estruturais. Nesse contexto, crê-se que os estados, nível de governo no Brasil que deve, dentre outras funções, apoiar a execução das políticas nacionais e municipais, e, a priori, tecnicamente com melhores condições para construção de portais eletrônicos, assumem papel importante para a produção e difusão de informações relacionadas ao processo de vacinação no âmbito de seus territórios. Resta saber se os portais eletrônicos dos estados brasileiros, objeto empírico da pesquisa, que surgiram em razão da legislação - ver Lei Complementar n. ${ }^{\circ} 131$ (2009), contribuem para a transparência da vacinação 
contra a Covid-19.

A motivação do estudo reside no fato de que a transparência e a Covid-19 são temas atuais e de destaque nas chamadas de trabalhos para publicações tanto no âmbito nacional como no internacional. Aqui esses temas são analisados conjuntamente em torno de suas conexões com fenômeno mais recente, o processo de vacinação contra a Covid-19, que se sabe foi iniciado no mundo em dezembro de 2020 e no Brasil em janeiro de 2021. Tal fenômeno mobiliza políticas relacionadas a questões epidemiológicas/sanitárias que, por sua vez, suscitam a aplicação de recursos públicos. Neste ínterim, tem a Contabilidade Pública a capacidade de contribuir com a disponibilização de informações qualificadas sobre os resultados obtidos com tais políticas.

À face do exposto, o artigo teve como objetivo caracterizar a contribuição dos portais eletrônicos dos estados brasileiros para a transparência do processo de vacinação contra a Covid19. Para tanto, os seguintes objetivos específicos foram estabelecidos: a) aplicar o instrumento de medição do Índice de Transparência da Vacinação contra a Covid-19 (ITVC-19) desses entes; b) verificar como o ITVC-19 se distribui ao longo do país; e c) identificar se houve evolução na transparência da vacinação no decorrer dos levantamentos efetuados.

A lacuna identificada na literatura diz respeito a pesquisas que investiguem a transparência do processo de vacinação, captada por meio de levantamento, em abril de 2021, na base de dados Spell. Justifica-se a importância da lacuna em termos teóricos e práticos, pois como nos lembram Santos e Mota (2020), a maior parte das pesquisas sobre transparência tem focado cenários de regularidade social, sendo necessário o empreendimento de esforços no intuito de avaliar de que forma os governos praticam esse fenômeno em situações de crises e incertezas (Santos \& Mota, 2020). Outrossim, não seria também exagero considerar que, como no Brasil a transparência permanece como um desafio por ser superado, a definição de um conjunto de dados essenciais e parâmetros para transparência poderá contribuir na padronização da divulgação de dados da pandemia no país, no caso particular do estudo o processo de vacinação (OKBR, 2020).

$\mathrm{O}$ artigo contribui com esta lacuna quando se debruça sobre o conteúdo dos portais dos estados para inferir sobre a transparência da vacinação contra a Covid-19. O estudo guiou-se pela aplicação do Índice de Transparência da Vacinação contra a Covid-19 (ITVC-19) e representa uma extensão de pesquisas anteriores (Raupp \& Pinho, 2020; Raupp et al., 2021). Os dados da pesquisa foram obtidos em seis levantamentos realizados a partir de análise nos portais, tendo como técnica de tratamento a análise de conteúdo. Mesmo que a maioria dos portais eletrônicos dos estados contribuam para a transparência da vacinação contra a Covid-19, observa-se estados cujo portais, por se situarem em níveis opaco, baixo e médio, parecem existir mais em razão de um imperativo tecnológico e menos em favor da transparência das ações governamentais.

\section{REVISÃO DE LITERATURA}

\subsection{Fragmentos da evolução da legislação sobre transparência no Brasil}

Quando se trata da transparência no Brasil de forma mais ampla, três marcos legais foram instituídos para regulamentar dispositivos da Constituição Federal de 1988: a Lei de Responsabilidade Fiscal (LRF), a Lei da Transparência e a Lei de Acesso à Informação (LAI). A LRF deu ênfase à transparência na gestão fiscal e definiu instrumentos que deveriam ser considerados para tal (Lei Complementar n. $\left.{ }^{\circ} 101,2000\right)$. Necessário mencionar também que a referida lei já mencionava que deveria ser dada ampla divulgação a tais instrumentos, inclusive em meios eletrônicos. A Lei da Transparência reforçou e ampliou alguns dispositivos da LRF, entretanto, o foco continuou sendo a gestão fiscal. No art. 48, parágrafo único, é assegurada a "liberação ao pleno conhecimento e acompanhamento da sociedade, em tempo real, de informações pormenorizadas sobre a execução orçamentária e financeira, em meios eletrônicos de 
acesso público" (Lei Complementar n. 131, 2009). A LAI também reforçou dispositivos já contemplados em legislações anteriores (LRF e Lei de Transparência, por exemplo), todavia, ampliou sobremaneira as informações para as quais deveria ser dada transparência, trouxe uma nova tipologia de transparência (transparência passiva), e definiu o sigilo como exceção.

As legislações anteriormente mencionadas, e outras que aqui não foram citadas, já poderiam, por si só, servir como basilares para divulgação de informações sobre o processo de vacinação, haja vista que se está falando de um tipo de informação pública. Ainda assim, deve-se trazer à luz legislações que tratam da transparência e que surgiram em meio ao cenário de pandemia. Dentre as legislações de emergência cita-se a Lei n. ${ }^{\circ} 13.979 / 2020$, cujo $\S 2^{\circ}$ do art. $4^{\circ}$ define para as contratações sua imediata disponibilização em sítio oficial (Lei n. ${ }^{\circ}$ 13.979, 2020).

Destaque-se também que no que se refere à vacinação contra a Covid-19, o Ministério da Saúde (MS) publicou portaria específica no sentido de favorecer a transparência desse processo imunizante. A Portaria GM/MS n. ${ }^{\circ} 69$ (2021), que instituiu a obrigatoriedade do registro das aplicações das vacinas nos sistemas de informação do próprio MS, exige, dentre outras informações, a identificação dos lotes e laboratórios, nome completo do vacinado, sexo, data de nascimento, número do CPF ou Cartão Nacional de Saúde e o tipo de dose aplicada. A necessidade da edição de instrumento normativo dessa natureza por si só já indica que ainda não se pode afirmar que exista no Brasil um "compromisso real com a transparência" (Michener et al., 2018, p. 613), mas sim que este conceito permanece dependente de novas formalizações para que se efetive no país, tanto em tempos regulares como em tempos de calamidades.

\subsection{Transparência como elemento da accountability}

O termo transparência é parte integrante do conceito de accountability, que embora ainda sem tradução direta para o idioma português, sabe-se que contempla outros, tais como: controle, obrigação de prestação de contas, justificativas para as ações que foram ou deixaram de ser empreendidas, recompensas, sejam essas na forma de premiação ou castigo, dentre outros (Pinho \& Sacramento, 2009). Considerando a bidimensionalidade que caracteriza o ciclo da accountability, proposta por Schedler (1999), a transparência situa-se especificamente na dimensão que o autor denomina por answerability, e que tem a informação e a justificação como atributos. A answerability é a etapa da accountability que diz respeito tanto à obrigação dos agentes públicos informarem e fornecerem explicações detalhadas sobre seus atos como ao direito de a sociedade obter tais informações e explicações com os detalhes necessários para que assim possa julgá-los.

Destaque-se que, no Brasil, desde a promulgação da Constituição de 1988, alterações institucionais têm sido implementadas a partir do plano federal que favorecem a prática dessa dimensão, portanto também a prática da transparência. Na pesquisa desenvolvida por Sacramento e Pinho (2016), por exemplo, onde se delineou a linha do tempo dessa específica dimensão até o ano de 2014, os pesquisadores caracterizam a trajetória da answerability no Brasil como contínua e desenvolvida de forma incremental. Esses autores pontuam que, desde a sua origem, questões de natureza financeira e orçamentária, motivam essa trajetória, e admitem que só recentemente outras matérias mais profundas da democracia - a exemplo do estabelecimento da Comissão Nacional da Verdade que buscou apurar violações de Direitos Humanos durante o período militar - passou a motivar o prosseguimento da trajetória da answerability no país (Pinho \& Sacramento, 2009).

Pode-se inferir, portanto, que transparência é "condição necessária, embora não suficiente, para a efetivação de qualquer ordem democrática, na medida em que só há controle efetivo dos governantes se seus atos forem adequadamente informados à sociedade" (Loureiro et al., 2008, p. 108). Dessa forma, "o compromisso real com a transparência, afinal, representa o fornecimento de informações suficientes para tornar governos suscetíveis a críticas” (Michener et al., 2018, p. 613).

Sabe-se que a transparência é fenômeno estudado a partir de diversos prismas, dentre os 
quais se destaca o que leva em consideração de quem partiu a iniciativa da ação (Zuccolotto, Teixeira, \& Riccio, 2015), designado por transparência ativa. Tal tipologia se refere à disponibilização de informações por iniciativa dos diferentes entes governamentais, voluntárias e/ou decorrentes de exigências legais (Lei Complementar n. ${ }^{\circ} 101,2000$; Lei Complementar n. ${ }^{\circ}$ 131, 2009; Lei n. ${ }^{\circ}$ 12.527, 2011), comumente veiculadas pelo portal eletrônico do próprio ente. Saliente-se que a Lei Federal n. ${ }^{\circ}$ 12.527, conhecida como Lei de Acesso à Informação (LAI), define informação como "dados, processados ou não, que podem ser utilizados para produção e transmissão de conhecimento, contidos em qualquer meio, suporte ou formato" (Lei n. ${ }^{\circ}$ 12.527, 2011).

Ademais, já existe estímulo para a efetivação da política de dados abertos no Brasil. O Decreto Federal n. ${ }^{\circ}$ 8.777, de 11 de maio de 2016, que instituiu a política de dados abertos do Executivo Federal, estabelece, dentre seus objetivos, o de promover a publicação de dados contidos em base de dados de órgãos e entidades da Administração Pública Federal, direta, autárquica e fundacional, e aprimorar a cultura da transparência pública (Decreto n. ${ }^{\circ} 8.777,2016$ ). Entende-se por dados abertos, ainda de acordo com o citado decreto, "os acessíveis ao público, representados em meio digital, estruturados em formato aberto, processáveis por máquina, referenciados na internet e disponibilizados sob licença aberta que permita sua livre utilização, consumo ou cruzamento, limitando-se a creditar a autoria ou a fonte" (Decreto n. ${ }^{\circ} 8.777,2016$ ).

\subsection{Transparência em época de crise}

Depreende-se que não há falta de mecanismos institucionais formais para a prática da transparência no âmbito da administração pública no Brasil. Contudo, pesquisas especificamente quanto à transparência governamental referente às ações relacionadas à pandemia da Covid-19 indicam que não se pode admitir o termo como absorvido pela cultura política brasileira no geral, muito embora avanços nesse sentido sejam reconhecidos. Dentre essas, pode-se citar Machado et al. (2020), que ao investigarem se as medidas que flexibilizaram prazos e procedimentos para o atendimento de pedidos de informação no período pandêmico tiveram impacto nos governos subnacionais, concluíram que o direito de acesso à informação pública é frágil e permanentemente tensionado no país. Em outro estudo, Pinho et al. (2020) constataram o não cumprimento dos requisitos legais de transparência dos dados sobre a disponibilização de informações essenciais e desejáveis nas contratações emergenciais para enfrentamento da Covid-19 em alguns municípioscapitais pesquisados.

Raupp e Pinho (2020, p. 3725) analisaram a construção da transparência sobre a Covid-19 pelos estados brasileiros e, "ainda que os dados possam revelar uma preocupação de alguns governos em construir melhores condições de disponibilização de informações sobre o novo coronavírus", entendem "que os estados ainda devem evoluir em transparência das informações". Para os autores "fica, então, a questão no ar se este episódio poderia se transformar em um ponto de inflexão no comprometimento dos governos aqui restritos aos estaduais e mobilização da sociedade para a construção de uma transparência mais efetiva" (Idem, p. 3736). Reforçam os autores a necessidade de pesquisa futuras, tanto no âmbito da Covid-19 como fora dele, o que reforça os achados de Santos e Mota (2020) que, ao promoverem reflexões sobre questões já evidentes em torno de como a transparência governamental, na atual conjuntura, tem se desenvolvido, concluem que o contexto é desafiador para a comunidade acadêmica especializada no tema. Entendem esses autores que há perguntas provocativas que necessitam de atenção dos pesquisadores, para que se avance no entendimento desse tipo de fenômeno.

Para Raupp et al. (2021, p. 15), que caracterizaram a prática da transparência ativa das capitais brasileiras na vacinação contra a Covid-19, pesquisa considerada inédita em âmbito 
nacional, os entes governamentais "passaram os últimos meses adaptando os seus portais para que pudessem disponibilizar informações sobre a Covid-19, desde questões epidemiológicas até contratações emergênciais". Pressupunham os autores que uma adaptação para informações sobre a vacinação tivesse ocorrido e/ou sido mais efetiva, fato que acabou não sendo confirmado. "Então, o que parece que nos falta mesmo é a transparência como um valor consolidado na realidade brasileira, e que pode ser explicado em parte por questões mais estruturais do contexto brasileiro" (Idem, p. 15).

Como se vê, a emergência da pandemia despertou estudos específicos sobre a transparência de diversos atos praticados pelo poder público. Contudo, como é notória uma lacuna a respeito da contribuição direta dos portais eletrônicos estaduais para a transparência do processo da vacinação, o estudo ora empreendido tem a pretensão de contribuir para o seu preenchimento.

\section{MÉTODO}

A pesquisa é do tipo descritiva, empreendida por meio de um estudo documental, com abordagem quali-quantitativa. O objeto de investigação compreende os portais eletrônicos dos 26 estados brasileiros e o Distrito Federal. Tal escolha é justificada sob diferentes prismas. Primeiro pelo fato de intermediarem a distribuição das vacinas aos municípios vindas do Governo Federal, tendo papel fundamental nessa direção. Em segundo por entender que os estados tendem a apresentar melhores condições, quando comparados aos municípios, financeiras e/ou técnicas de apresentarem portais mais estruturados em termos de requisitos de transparência, contribuindo, inclusive, para a construção da accountability. Por fim, e ainda comparando aos municípios, os estados estão mais distantes da população, e pressupõe-se que as tecnologias da informação e comunicação possam suprir, ao menos em parte, a ausência deste contato presencial.

$\mathrm{O}$ estudou guiou-se pela aplicação do Índice de Transparência da Vacinação contra a Covid-19 (ITVC-19), cujas dimensões, critérios e respectivas pontuações estão apresentados na Figura 1.

\begin{tabular}{|c|c|c|c|}
\hline Dimensão & Critério & $\begin{array}{c}\text { Descrição } \\
\end{array}$ & Pontuação \\
\hline \multirow{6}{*}{ Conteúdo } & $\begin{array}{l}\text { Doses } \\
\text { disponíveis }\end{array}$ & $\begin{array}{l}\text { Quantidade de doses que o estado/município } \\
\text { dispõe }\end{array}$ & $\begin{array}{l}0=\text { não apresenta; } \\
1=\text { apresenta. }\end{array}$ \\
\hline & $\begin{array}{l}\text { Idade ou Faixa } \\
\text { Etária }\end{array}$ & Doses aplicadas por idade ou faixa etária & $\begin{array}{l}0=\text { não apresenta; } \\
0,5=\text { apresenta uma média geral; } \\
1=\text { apresenta idade ou faixa etária. }\end{array}$ \\
\hline & Sexo & Doses aplicadas por sexo & $\begin{array}{l}0=\text { não apresenta; } \\
0,5=\text { apresenta uma média geral } \\
1=\text { apresenta sexo. }\end{array}$ \\
\hline & População alvo & Doses aplicadas por população alvo & $\begin{array}{l}0=\text { não apresenta; } \\
0,5=\text { apresenta uma média geral; } \\
1=\text { apresenta }\end{array}$ \\
\hline & Tipo de dose & Doses aplicadas por primeira e segunda doses & $\begin{array}{l}0=\text { não apresenta } \\
1=\text { apresenta }\end{array}$ \\
\hline & Tipo de vacina & Doses aplicadas por tipo de vacina & $\begin{array}{l}0=\text { não apresenta; } \\
1=\text { apresenta }\end{array}$ \\
\hline Granularidade & Localização & $\begin{array}{l}\text { Nível de agregação geográfica das doses } \\
\text { aplicadas (por município, por estabelecimento } \\
\text { de saúde etc.) }\end{array}$ & $\begin{array}{l}0=\text { não apresenta; } \\
1=\text { apresenta }\end{array}$ \\
\hline \multirow{3}{*}{ Formato } & Visualização & Painel para consulta do público em geral & $\begin{array}{l}0=\text { não apresenta; } \\
0,5=\text { apresenta boletim e/ou notícias; } \\
1=\text { apresenta painel. }\end{array}$ \\
\hline & Formato aberto & $\begin{array}{l}\text { Dados estruturados em ao menos uma planilha } \\
\text { em formato editável, de preferência aberto } \\
\text { (CSV, ODS) }\end{array}$ & $\begin{array}{l}0=\text { não apresenta; } \\
1=\text { apresenta }\end{array}$ \\
\hline & Série histórica & $\begin{array}{l}\text { Base única e atualizada com o histórico } \\
\text { completo, desde o início da aplicação }\end{array}$ & $\begin{array}{l}0=\text { não apresenta; } \\
1=\text { apresenta }\end{array}$ \\
\hline
\end{tabular}

Figura 1. Modelo de análise

Fonte: Raupp et al. (2021, p. 6-7). 
A dimensão Conteúdo considera "parâmetros que podem auxiliar na produção de análises mais aprofundadas sobre a disseminação do novo coronavírus pelo país. Cada indicador recebe Peso 1 na composição do Índice" (OKBR, 2020, p. 6). A Granularidade "é a dimensão que avalia o detalhamento dos dados divulgados pelas autoridades, fornecendo uma camada extra de informação. Cada indicador recebe Peso 3 na composição do Índice" (OKBR, 2020, p. 14). Já no Formato avalia-se "de que maneira os dados foram disponibilizados. A forma de acessar, ler e compartilhar os dados é um determinante do potencial de análise dos mesmos. Cada indicador recebe Peso 5 na composição do Índice" (OKBR, 2020, p. 15). As dimensões são de natureza qualitativa e quantitativa, por exemplo, o critério 'doses disponíveis' é quantitativo, mas o critério 'visualização' é qualitativo.

De acordo com Raupp et al. (2021), o ITVC-BR teve sua primeira versão baseada no Índice de Transparência da Covid-19 (ITC-19) elaborado pela Open Knowledge Brasil (OKBR). Com a primeira versão do índice foi realizado um pré-teste com as capitais brasileiras, onde foram identificados ajustes necessários, resultando na segunda e mais atual versão do ITVC-BR. O índice adotou a escala de 0 a 100 do ITC-19 (OKBR, 2020), em que 0 é atribuído ao estado menos transparente, e 100 ao mais transparente. Os níveis de transparência foram definidos a partir de intervalos de pontuação, sendo os seguintes: opaco (0 - 19); baixo (20 - 39); médio (40 - 59); bom (60 - 79); alto (80 - 100).

Os dados da pesquisa foram obtidos em seis levantamentos realizados a partir de análise nos portais, respectivamente em 30-04-2021, 07-05-2021, 14-05-2021, 21-05-2021, 28-05-2021 e 04-06-2021, além de comunicação por e-mails com os estados. Em cada levantamento foram realizadas três etapas, sempre na mesma sequência: coleta de dados nos portais; cálculo preliminar do ITVC-19 e envio aos estados para conferência e indicação de possíveis ajustes; e análise dos dados. Ressalta-se que a adoção do ITVC-BR não era compulsória por parte dos estados.

As coletas eram realizadas sempre às sextas-feiras e, logo após finalizadas, os resultados eram encaminhados ao setor de comunicação dos estados para que pudessem efetuar a conferência. Considerou-se como tempo de resposta o intervalo entre a data de envio e a véspera da coleta subsequente. Ainda que não tenham sido identificadas divergências pelos estados em suas conferências, foram percebidos avanços por alguns entes em coletas posteriores no sentido de busca atender os critérios do ITVC-BR. Os dados considerados para análise foram aqueles obtidos após a conferência do setor de comunicação dos estados.

Os dados foram coletados diretamente nos portais eletrônicos dos estados, por meio de protocolo de observação, cujas seções estão descritas na Figura 2. O protocolo de observação baseou-se no modelo de análise e teve a intenção de guiar o processo de coleta de dados, de modo a possibilitar a investigação das dimensões e seus respectivos critérios utilizados para inferir sobre a transparência da vacinação contra a Covid-19.

\begin{tabular}{|l|l|}
\hline \multicolumn{1}{|c|}{ Estado } & \multicolumn{1}{c|}{ Seção principal de coleta } \\
\hline Acre & http://covid19.ac.gov.br/vacina/inicio \\
\hline Alagoas & https://www.saude.al.gov.br/vacinacao-contra-a-covid-19/ \\
\hline Amapá & http://painel.corona.ap.gov.br/vacina/ \\
\hline Amazonas & https://www.fvs.am.gov.br/indicadorSalaSituacao_view/75/2 \\
\hline Bahia & https://bi.saude.ba.gov.br/vacinacao/ \\
\hline Ceará & https://coronavirus.ceara.gov.br/servicos/vacina/ \\
\hline Distrito Federal & http://www.saude.df.gov.br/vacinometro/ \\
\hline Espírito Santo & https://coronavirus.es.gov.br/painel-vacinacao \\
\hline Goiás & encurtador.com.br/IKOV7 \\
\hline Maranhão & https://painel-covid19.saude.ma.gov.br/vacinas \\
\hline Mato Grosso & http://www.saude.mt.gov.br/paineldistribuicaovacinasmt/ \\
\hline
\end{tabular}




\begin{tabular}{|l|l|}
\hline Mato Grosso do Sul & encurtador.com.br/mpDNX \\
\hline Minas Gerais & https://coronavirus.saude.mg.gov.br/vacinometro \\
\hline Pará & https://www.saude.pa.gov.br/vacinometro/ \\
\hline Paraíba & https://paraiba.pb.gov.br/diretas/saude/coronavirus/painel-de-vacinacao \\
\hline Paraná & http://www.coronavirus.pr.gov.br/vacinacao-ranking \\
\hline Pernambuco & encurtador.com.br/beKM8 \\
\hline Piauí & encurtador.com.br/chwV9 \\
\hline Rio de Janeiro & https://vacinacaocovid19.saude.rj.gov.br/vacinometro \\
\hline Rio Grande do Norte & https://rnmaisvacina.lais.ufrn.br/transparencia/vacinacao/ \\
\hline Rio Grande do Sul & https://vacina.saude.rs.gov.br/ \\
\hline Rondônia & https://covid19.sesau.ro.gov.br/Home/Vacina \\
\hline Roraima & https://saude.rr.gov.br/vacinometro/ \\
\hline Santa Catarina & https://www.coronavirus.sc.gov.br/vacinacao/ \\
\hline São Paulo & https://vacinaja.sp.gov.br/vacinometro/ \\
\hline Sergipe & https://todoscontraocorona.net.br/inicial-vacinas/ \\
\hline Tocantins & http://integra.saude.to.gov.br/covid19/Vacinometro \\
\hline
\end{tabular}

Figura 2. Seção de coleta de dados

Fonte: Dados da pesquisa (2021).

As coletas foram realizadas sempre às sextas-feiras, com intervalos semanais, e consideraram informações disponibilizadas ao longo da semana. Após cada coleta os resultados foram encaminhados ao setor de comunicação de cada estado para que pudessem fazer a conferência e indicar alguma incoerência na coleta, caso fosse necessário, ou mesmo direcionar a conferência para um setor mais apropriado para tal. A última etapa da pesquisa consistiu na análise dos dados, tendo como técnica a análise de conteúdo, cujos resultados e discussões são apresentados na próxima seção.

\section{RESULTADOS}

Inicialmente são apresentados os resultados por levantamento efetuado, com destaque para pontuação, nível e posição dos estados, conforme pode ser observado na Tabela 1. A coluna pontuação é decorrência das pontuações individualizadas dos critérios em cada uma das dimensões, conforme pesos identificados na seção de método. Como consequência da pontuação chegou-se às colunas nível e posição. 
Tabela 1

Pontuação, nível e posição dos Estados nos levantamentos realizados

\begin{tabular}{|c|c|c|c|c|c|c|c|c|c|c|c|c|c|c|c|c|c|c|c|c|c|c|c|}
\hline \multicolumn{4}{|c|}{$1^{\circ}$ levantamento } & \multicolumn{4}{|c|}{$2^{\circ}$ levantamento } & \multicolumn{4}{|c|}{$3^{\circ}$ levantamento } & \multicolumn{4}{|c|}{$4^{\circ}$ levantamento } & \multicolumn{4}{|c|}{$5^{\circ}$ levantamento } & \multicolumn{4}{|c|}{$6^{\circ}$ levantamento } \\
\hline 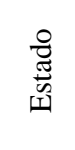 & 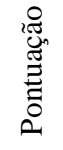 & $\stackrel{D}{\stackrel{D}{z}}$ & 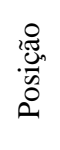 & 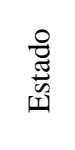 & 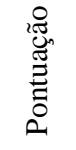 & $\stackrel{\vec{D}}{\stackrel{\mathrm{Z}}{\mathrm{Z}}}$ & 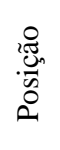 & 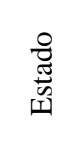 & 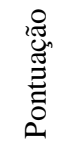 & 总 & 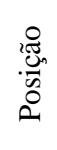 & 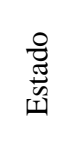 & 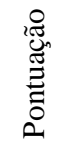 & $\stackrel{\Xi}{\Xi}$ & 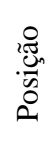 & 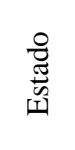 & 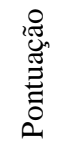 & $\stackrel{\Xi}{\stackrel{D}{Z}}$ & 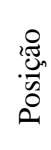 & $\begin{array}{l}\stackrel{0}{\vec{Z}} \\
\frac{\pi}{5} \\
\text { I }\end{array}$ & 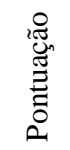 & $\stackrel{\vec{D}}{\stackrel{\vec{z}}{z}}$ & 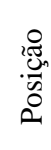 \\
\hline SP & 100 & Alto & 1 & $\mathrm{AC}$ & 100 & Alto & 1 & $\mathrm{AC}$ & 100 & Alto & 1 & $\mathrm{AC}$ & 100 & Alto & 1 & $\mathrm{AC}$ & 100 & Alto & 1 & $\mathrm{AC}$ & 100 & Alto & 1 \\
\hline $\mathrm{AC}$ & 96 & Alto & 2 & $\mathrm{RS}$ & 100 & Alto & 1 & $\mathrm{RS}$ & 100 & Alto & 1 & $\mathrm{RS}$ & 100 & Alto & 1 & $\mathrm{RS}$ & 100 & Alto & 1 & $\mathrm{RS}$ & 100 & Alto & 1 \\
\hline $\mathrm{BA}$ & 92 & Alto & 3 & TO & 96 & Alto & 2 & MG & 96 & Alto & 2 & GO & 96 & Alto & 2 & GO & 96 & Alto & 2 & RO & 98 & Alto & 2 \\
\hline TO & 92 & Alto & 3 & BA & 92 & Alto & 3 & TO & 96 & Alto & 2 & MG & 96 & Alto & 2 & MG & 96 & Alto & 2 & GO & 96 & Alto & 3 \\
\hline RS & 90 & Alto & 4 & GO & 92 & Alto & 3 & $\mathrm{BA}$ & 92 & Alto & 3 & TO & 96 & Alto & 2 & TO & 96 & Alto & 2 & MA & 96 & Alto & 3 \\
\hline MG & 88 & Alto & 5 & MG & 88 & Alto & 4 & GO & 92 & Alto & 3 & BA & 92 & Alto & 3 & BA & 92 & Alto & 3 & MG & 96 & Alto & 3 \\
\hline GO & 71 & Bom & 6 & SP & 88 & Alto & 4 & SP & 92 & Alto & 3 & SP & 92 & Alto & 3 & SP & 92 & Alto & 3 & TO & 96 & Alto & 3 \\
\hline RN & 71 & Bom & 6 & DF & 79 & Bom & 5 & RR & 75 & Bom & 4 & DF & 77 & Bom & 4 & RR & 79 & Bom & 4 & BA & 92 & Alto & 4 \\
\hline RR & 71 & Bom & 6 & RN & 75 & Bom & 6 & DF & 73 & Bom & 5 & RO & 75 & Bom & 5 & DF & 77 & Bom & 5 & SP & 92 & Alto & 4 \\
\hline ES & 67 & Bom & 7 & RO & 75 & Bom & 6 & PR & 71 & Bom & 6 & PR & 71 & Bom & 6 & MS & 75 & Bom & 6 & AP & 79 & Bom & 5 \\
\hline MS & 67 & Bom & 7 & ES & 71 & Bom & 7 & PI & 71 & Bom & 6 & PI & 71 & Bom & 6 & PR & 71 & Bom & 7 & ES & 79 & Bom & 5 \\
\hline PI & 67 & Bom & 7 & PR & 71 & Bom & 7 & RO & 71 & Bom & 6 & RN & 71 & Bom & 6 & PI & 71 & Bom & 7 & RR & 79 & Bom & 5 \\
\hline SE & 67 & Bom & 7 & PI & 71 & Bom & 7 & SE & 71 & Bom & 6 & RO & 71 & Bom & 6 & $\mathrm{RN}$ & 71 & Bom & 7 & DF & 77 & Bom & 6 \\
\hline $\mathrm{AM}$ & 50 & Médio & 8 & RR & 71 & Bom & 7 & RN & 67 & Bom & 7 & SE & 71 & Bom & 6 & RO & 71 & Bom & 7 & MS & 75 & Bom & 7 \\
\hline $\mathrm{DF}$ & 50 & Médio & 8 & SE & 67 & Bom & 8 & MS & 50 & Médio & 8 & MS & 67 & Bom & 7 & SE & 71 & Bom & 7 & SE & 75 & Bom & 7 \\
\hline RO & 50 & Médio & 8 & AP & 54 & Médio & 9 & PA & 50 & Médio & 8 & MA & 54 & Médio & 8 & MA & 54 & Médio & 8 & PR & 71 & Bom & 8 \\
\hline MA & 46 & Médio & 9 & $\mathrm{AM}$ & 54 & Médio & 9 & RJ & 50 & Médio & 8 & PA & 50 & Médio & 9 & PA & 50 & Médio & 9 & PI & 71 & Bom & 8 \\
\hline RJ & 46 & Médio & 9 & MA & 50 & Médio & 10 & $\mathrm{SC}$ & 50 & Médio & 8 & RJ & 50 & Médio & 9 & RJ & 50 & Médio & 9 & $\mathrm{RN}$ & 71 & Bom & 8 \\
\hline AP & 42 & Médio & 10 & MS & 50 & Médio & 10 & ES & 46 & Médio & 9 & $\mathrm{SC}$ & 50 & Médio & 9 & $\mathrm{SC}$ & 50 & Médio & 9 & $\mathrm{SC}$ & 71 & Bom & 8 \\
\hline $\mathrm{PA}$ & 42 & Médio & 10 & $\mathrm{SC}$ & 50 & Médio & 10 & MA & 46 & Médio & 9 & ES & 46 & Médio & 10 & ES & 46 & Médio & 10 & $\mathrm{CE}$ & 50 & Médio & 9 \\
\hline MT & 38 & Baixo & 11 & PA & 46 & Médio & 11 & MT & 42 & Médio & 10 & MT & 42 & Médio & 11 & CE & 42 & Médio & 11 & $\mathrm{PA}$ & 50 & Médio & 9 \\
\hline PR & 29 & Baixo & 12 & RJ & 46 & Médio & 11 & $\mathrm{~PB}$ & 29 & Baixo & 11 & PB & 29 & Baixo & 12 & MT & 42 & Médio & 11 & RJ & 50 & Médio & 9 \\
\hline $\mathrm{PE}$ & 29 & Baixo & 12 & MT & 42 & Médio & 12 & $\mathrm{AP}$ & 21 & Baixo & 12 & $\mathrm{CE}$ & 25 & Baixo & 13 & $\mathrm{~PB}$ & 29 & Baixo & 12 & MT & 42 & Médio & 10 \\
\hline PB & 25 & Baixo & 13 & PB & 29 & Baixo & 13 & $\mathrm{AM}$ & 21 & Baixo & 12 & PE & 25 & Baixo & 13 & $\mathrm{PE}$ & 25 & Baixo & 13 & $\mathrm{~PB}$ & 29 & Baixo & 11 \\
\hline $\mathrm{SC}$ & 25 & Baixo & 13 & $\mathrm{AL}$ & 25 & Baixo & 14 & $\mathrm{PE}$ & 17 & Opaco & 13 & $\mathrm{AP}$ & 21 & Baixo & 14 & AP & 21 & Baixo & 14 & $\mathrm{PE}$ & 25 & Baixo & 12 \\
\hline $\mathrm{CE}$ & 21 & Baixo & 14 & $\mathrm{CE}$ & 21 & Baixo & 15 & $\mathrm{AL}$ & 4 & Opaco & 14 & AM & 21 & Baixo & 14 & AM & 21 & Baixo & 14 & AM & 21 & Baixo & 13 \\
\hline $\mathrm{AL}$ & 0 & Opaco & 15 & $\mathrm{PE}$ & 13 & Opaco & 16 & $\mathrm{CE}$ & 0 & Opaco & 15 & $\mathrm{AL}$ & 4 & Opaco & 15 & $\mathrm{AL}$ & 4 & Opaco & 15 & $\mathrm{AL}$ & 4 & Opaco & 14 \\
\hline
\end{tabular}

Fonte: Dados da pesquisa (2021). 
Neste primeiro levantamento, realizado em 30 de abril de 2021, somente 6 estados $(22,22 \%)$ ficaram no nível ideal de transparência, ou seja, no nível alto, tendo o estado de São Paulo a primeira posição. Pode-se dizer que o nível bom é também uma condição satisfatória de transferência, e foi identificado em outros 7 estados $(25,92 \%)$. Se forem somados os estados com nível alto, bom e médio (estados com uma condição próxima de bom), é possível afirmar que o conjunto de entes investigados não estão distante da situação desejável de transparência no processo de vacinação contra a Covid-19. Por outro lado, deve-se pontuar aqueles que estão em patamares inferiores, níveis baixo e opaco, que juntos representam 7 estados $(25,92 \%)$.

$\mathrm{Na}$ análise individualizada os critérios doses disponíveis e sexo foram os menos atendidos. Esses dados chamam a atenção sobretudo em relação ao critério sexo, pois o próprio Plano Nacional de Operacionalização da Vacinação contra a Covid-19 (Lei n. ${ }^{\circ}$ 13.979, 2020) definiu que seria colocado à disposição do público em geral os dados que dizem respeito ao número de doses aplicadas, por estado e município, em um dado período de tempo, por gênero, por faixa etária e por tipo de vacina. No outro extremo os itens mais atendidos foram população- alvo, tipo de dose, localização e visualização.

Deve-se atentar para o fato de que o primeiro levantamento ocorreu três meses após o início da vacinação no Brasil, em 17 de janeiro, quando a primeira pessoa vacinada no Brasil recebeu a primeira dose da Coronavac. Mesmo entendendo que os resultados pudessem ser mais animadores, é necessário ressaltar que os estados não estavam preparados (recursos humanos, financeiros e tecnológicos) para atender ao processo de transparência na vacinação. Por outro lado, é de supor também que do ponto de visto técnico não seria tão difícil esse ajuste, visto que já vinham trabalhando com a transparência sobre a questão sanitária/epidemiológica mais ampla da Covid19. Prova disso é o fato de que estados bem ranqueados (Acre, Goiás e Rio Grande do Sul) neste primeiro levantamento apresentaram, inclusive, dados sobre doses aplicadas por raça/cor, ou seja, item além daqueles que constam no modelo de análise.

A partir do segundo levantamento, realizado em 07 de maio de 2021, passou-se a considerar atendido o critério doses disponíveis caso o estado fornecesse dados sobre vacinas recebidas e aplicadas, ou sobre doses distribuídas e doses aplicadas. Alguns estados, inclusive, apresentam informações além daquelas esperadas, como ocorre com o estado do Acre que apresenta uma seção exclusiva para informações sobre vacina recebidas, com dados sobre quantidades, valores, lotes, fabricantes, disponibilizadas por data de recebimento. Considerando a informação sobre vacinas disponíveis, o Acre chega na pontuação máxima. Há também uma seção específica para as vacinas distribuídas, que traz dados por regionais de saúde, por secretarias municipais de saúde, cujas informações também são dispostas de forma diária. Por outro lado, os boletins sobre a vacinação continuam desatualizados, o que leva a crer que podem ter sido abandonados em razão de as informações estarem sendo disponibilizadas no painel.

Em alguns estados foi observada a disponibilização de dados sobre o percentual de vacinados. Os estados do Amapá e do Amazonas, por exemplo, apresentam o percentual de vacinados por primeira e segunda dose aplicadas. Ainda em relação ao estado do Amazonas, apesar da possibilidade de baixar os dados em formato aberto, este indicador não foi pontuado, pois são mínimas as informações disponíveis neste formato. Aliás, esta é uma característica, ou seja, quem apresenta a possibilidade de formato aberto acaba apresentando um conjunto ínfimo de dados, normalmente inferior àquilo que está disponível no próprio painel. Já no estado do Maranhão, o formato aberto não foi considerado pois as informações estavam desatualizadas.

Neste levantamento, 7 estados $(25,92 \%)$ receberam nível alto de transparência, sendo que os estados do Acre e Rio Grande do Sul dividiram a primeira posição com pontuação máxima. Já o nível bom foi observado em 8 estados $(29,62 \%)$. Quando se soma o número de estados com nível alto, bom e médio, este dado passou de 20 estados (74,07\%) no primeiro levantamento para 23 estados $(885,18 \%)$ no segundo levantamento. Consequentemente, identificou-se uma redução no 
número de estados com nível baixo de transparência, do primeiro para o segundo levantamento, passando de 6 estados $(22,22 \%)$ para 3 estados $(11,11 \%)$. Na análise individualizada o critério doses disponíveis passou a fazer parte do conjunto de itens mais atendidos, juntamente com população-alvo, tipo de dose, localização e visualização. O critério sexo continua na categoria de menos atendidos.

No terceiro levantamento, feito em 14 de maio de 2021, percebeu-se que os estados de Alagoas, Ceará, Paraíba e Pernambuco permaneceram nos níveis inferiores (baixo e opaco) nos três primeiros levantamentos. Para o estado de Alagoas, por exemplo, foi considerada como fonte de informação o boletim de imunização, sendo o tipo de dose aplicada o único dado requerido para o índice que foi identificado. Ceará, de forma semelhante, mantém um site com informações mínimas sobre a vacinação. Outra característica evidenciada neste levantamento foi a ausência de data de atualização das informações em alguns portais. Os estados do Amapá e Amazonas disponibilizam várias informações, porém não foi encontrada a data de atualização. Para estes dois portais o único dado considerado foi a existência de um painel com informações, que atende ao critério visualização.

Embora com algumas posições diferentes, mantiveram-se com nível alto de transparência os mesmos estados com este nível no segundo levantamento, 7 estados $(25,92 \%)$. Em relação ao nível bom, o estado do Espírito Santo deixou este nível e passou a integrar o conjunto de estados com nível médio de transparência, já que se identificou que a maioria das informações disponibilizadas por este estado se referiam às doses distribuídas e não às doses aplicadas, que é o foco da maioria dos critérios da dimensão conteúdo. O nível médio também teve uma redução no número total de estados com este nível se comparado ao segundo levantamento. A redução no número de estados com níveis bom e médio, consequentemente, abriu espaço para que fossem identificadas elevações nos extratos inferiores, baixo e opaco, agora com 3 estados $(11,11 \%)$ cada um. Na análise micro, o critério sexo continua sendo o menos atendido, enquanto, doses disponíveis, tipo de dose, localização, e visualização, foram os critérios com o maior número de ocorrência nos estados.

Constatou-se no quarto levantamento, realizado em 21 de maio de 2021, que se mantiveram no nível alto de transparência os mesmos sete estados dos levantamentos anteriores, $(25,92 \%)$. Em relação ao nível bom, a novidade foi a integração do estado do Mato Grosso do Sul, que deixou o nível médio por passar a indicar a faixa etária dos seus vacinados. Portanto, o nível bom agora abriga oito entes, e o médio seis, os mesmos seis do terceiro levantamento (PA, RJ, SC, ES, MA e MT). No que se refere ao nível baixo, observou-se um aumento de dois entes, quais sejam, CE que passou a evidenciar as doses disponíveis - e PE - que passou a indicar os municípios dos vacinados - o que fez o nível baixo agora abrigar cinco estados. Com isso, o nível opaco passou a ser exclusivo do estado de Alagoas, pois só disponibiliza uma "nota de distribuição", sendo a última com data de 04/05, cuja redação utiliza verbos no tempo futuro (p. ex. "Todas as doses da CoronaVac serão destinadas à...”; “Assim, serão distribuídas 7.620 doses (D1), para a conclusão desse grupo prioritário"), o que não nos permite inferir a respeito de sua concretização.

Com referência às constatações do quinto levantamento, efetuado em 28 de maio, têm-se que no nível alto se mantiveram os mesmos sete estados dos levantamentos anteriores, e todos com a mesma pontuação verificada no quarto levantamento (AC, RS, MG, TO, BA, GO e SP). A mesma situação foi constatada no nível bom com referência ao número de entes - oito -, sendo que RR, DF e MS alteraram positivamente suas pontuações, pois RR e DF passaram a disponibilizar informações para o critério sexo dos vacinados e MS a disponibilizar a série histórica no formato data. No que se refere aos demais níveis, viu-se que o nível médio passou a contar com sete estados pelo motivo de o CE ter passado a informar a localização dos vacinados, fato que o fez deixar de ocupar o nível baixo. Os demais estados permaneceram com a mesma 
pontuação, portanto não alteraram a sua posição na escala do ITVC-19: PB, PE, AP e AM no nível baixo; AL - sozinho - no opaco. Na análise micro fica constatado que o critério sexo continua sendo o menos atendido, embora mais dois estados tenham passado a evidenciar essa informação. Já os critérios doses disponíveis, tipo de dose, localização, e visualização permanecem com o maior número de ocorrência nos estados.

Destaque-se que dos e-mails enviados aos entes pesquisados nesse levantamento, dois deles responderam trazendo informações para os pesquisadores - Rondônia e Santa Catarina sendo que Rondônia informou que "o sistema de dados que dá transparência à vacinação realizada no estado de Rondônia está em fase de ajustes, que poderá contemplar as solicitações mencionadas na pesquisa". Já Santa Catarina informou que "lançou no dia 31 de maio, o Vacinômetro, um painel interativo onde é possível consultar, em tempo real, as informações de doses aplicadas da vacina contra a COVID-19 em Santa Catarina".

O sexto levantamento foi efetuado no dia 06 de junho, quando se observou o ingresso de mais dois estados no nível alto, Rondônia e Maranhão, que até o quinto levantamento ocupavam os níveis bom e médio respectivamente. Assim, o nível alto, passou a abrigar nove estados: RO, MA, AC, RS, MG, TO, BA, GO e SP. Saliente-se que o ingresso de Rondônia nesse nível foi consequência da disponibilização de informações quanto a sexo, tipo de vacina e série histórica dos vacinados, cumprindo o que afirmou no e-mail enviado aos pesquisadores. Já o Maranhão passou a disponibilizar em dados abertos e informar a série histórica dos vacinados.

No nível bom também ingressaram dois entes, o Amapá e o Espírito Santo, o que faz esse nível abrigar o maior número de entes - 10 (AP, DF, ES, MS, PR, PI, RN, RR, SC e SE). O ingresso do Amapá nesse nível foi consequência da disponibilização de uma planilha com dados abertos contendo os indicadores exigidos para o ITVC-19. Nessa planilha, contudo, constatou-se que a última modificação ocorreu no dia 31 de maio, o que já configura certo atraso na disponibilização dos dados. Já o ingresso do estado do Espírito Santo decorreu do fato de, nesse levantamento, o único indicador não localizado no seu painel ter sido o da série histórica. Outro avanço verificado foi a criação do Vacinômetro de Santa Catarina, confirmando também a informação constante na resposta dada ao e-mail enviado pelos pesquisadores.

No que se refere aos demais níveis, viu-se que o nível médio agora conta com apenas quatro entes, pelo motivo de ES e SC terem passado para o nível bom e MA para o nível alto. Assim, permaneceram no nível médio: CE, MT, PA e RJ. Também no nível baixo foi reduzido o número total de entes, pois, como já afirmado, o Estado do Amapá agora integra o nível bom, ficando no nível baixo de transparência apenas PB, PE e AM. Já AL conserva a sua performance, permanecendo sozinho no nível opaco. $\mathrm{Na}$ análise micro fica constatado que o critério sexo continua sendo o menos atendido, seguido dos critérios tipo de vacina, formato aberto, e série histórica.

\section{DISCUSSÕES}

Considerando que o $6^{\circ}$ levantamento contemplou o último e mais atual diagnóstico sobre a transparência dos estados no processo de vacinação, buscou-se mais detidamente discutir seus resultados. Para tanto, incialmente apresenta-se a Figura 3 cujo mapa da transparência dos dados da vacinação nos estados - ITVC-19 sintetiza os dados obtidos. 


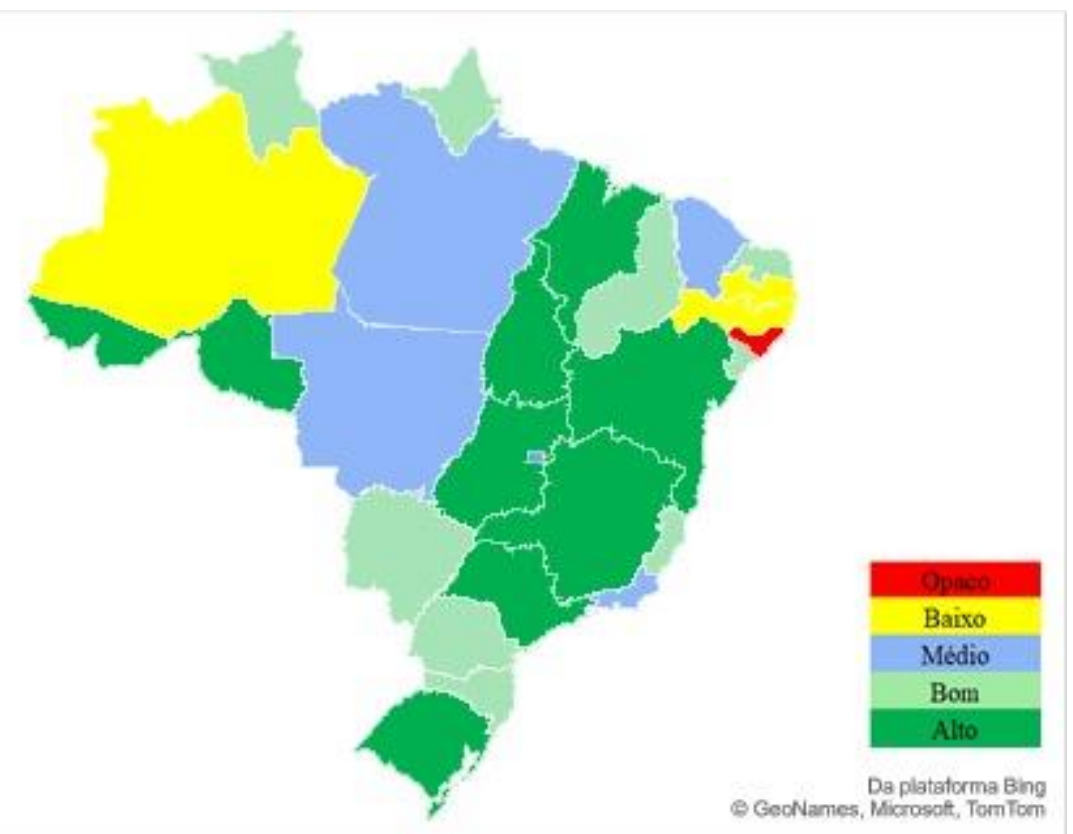

Figura 3. Transparência dos dados da vacinação nos estados - ITVC-19 ( $6^{\circ}$ levantamento) Fonte: Dados da pesquisa (2021).

Como pode ser observado no disposto na Figura 3, quando do fechamento desse estudo, todos os níveis do ITVC-19 foram identificados no país, estando distribuídos da seguinte forma pelas regiões: o opaco, somente se verificou na Região Nordeste (AL); o baixo, no Nordeste (PE e PB) e no Norte (AM); o médio, no Nordeste (CE), Centro-Oeste (MT), Norte (PA) e Sudeste (RJ); o bom, no Nordeste (PI, RN e SE), Centro-Oeste (DF e MS), Norte (AP e RR), Sudeste (ES) e Sul (PR e SC); e o alto, no Nordeste (MA e BA), Centro-Oeste (TO e GO), no Norte (RO, AC), no Sudeste (MG e SP) e no Sul (RS). Os destaques mais positivos são Acre e Rio Grande do Sul, que obtiveram pontuação máxima (100) do segundo ao sexto levantamento; o destaque negativo é Alagoas, pois figurou no nível baixo em um dos levantamentos e opaco nos outros cinco. Esse cenário, onde apenas dois estados obtiveram pontuação máxima no ITVC-19, coaduna-se com os achados Pinho et al. (2020), pois evidenciou que a transparência se constitui em um desafio para o país, uma vez que dados desejáveis sobre o processo de transparência da vacinação no país não estão disponíveis e/ou abertos ao público.

Trata-se de um contexto cuja ausência de compromisso com a transparência impede o fornecimento de informações capazes de tornar os estados suscetíveis a críticas no que se refere à transparência do processo de vacinação contra a Covid-19 (Michener et al., 2018). Os resultados coadunam com aqueles obtidos por Machado et al. (2020), já que também concluíram que o acesso à informação pública é frágil e constantemente tensionado no país. Mesmo que o objeto empírico seja diferente, o estudo de Machado et al. (2020) também tratou da transparência em um período pandêmico.

No decorrer dos seis levantamentos efetuados foram observados avanços pelos estados, inclusive saindo de níveis inferiores para níveis com um grau satisfatório de atendimento aos requisitos da transparência sobre o processo de vacinação. Estes resultados encontram respaldo em Raupp e Pinho (2020, p. 3736), para quem "os avanços detectados neste curto e tenso período de tempo pode nos servir de base para pensar a questão da transparência no Brasil de um ponto de vista mais estrutural". As respostas se assemelham àquelas obtidas por Raupp e Pinho (2020), ou seja, positivas até o momento, findado o sexto levantamento. Oportuno também apresentar que, 
segundo Raupp e Pinho (2020, p. 3736-3737), "tal fato pode se dever à magnitude e implicações que a pandemia tem, afetando praticamente toda a população, o que mobilizou os governos a darem respostas em tempo célere à sociedade".

Merece uma reflexão o fato de que o levantamento iniciou em abril de 2021, na sequência e em complemento ao estudo de Raupp e Pinho (2020), e mais de um ano após o decreto de pandemia no Brasil. Transcorrido todo esse tempo, os estados ainda não divulgam todas as informações nos portais eletrônicos. Mesmo após um ano decorrido, alguns estados ainda permanecem em nível inferior em relação à transparência da vacinação. Os resultados também corroboram achados de Raupp et al. (2021), pois ainda há estados com informações desatualizadas, informações fragmentas em diferentes seções do portal, e ausência de padronização na forma de veiculação da informação que pode ser por meio de notícias, informes, boletins epidemiológicos e/ou painéis.

Neste caso, os resultados com a transparência na vacinação podem evidenciar também o quanto os estados são accountables neste sentido (Pinho \& Sacramento, 2009), com indicativos de que precisam evoluir em termos de answerability (Schedler, 1999), o que reforça a ideia de que no Brasil a trajetória desta dimensão é contínua e desenvolvida de forma incremental (Sacramento \& Pinho, 2016). Não é demais lembrar que "isso pode se dever ao fato da situação de 'guerra' que o sistema de saúde vem enfrentando, e agora um desafio nunca antes observado" (Raupp \& Pinho, 2020, p. 3736).

\section{CONCLUSÕES, CONTRIBUIÇÕES E ESTUDOS FUTUROS}

O artigo teve por objetivo caracterizar a contribuição dos portais eletrônicos dos estados brasileiros para a transparência do processo de vacinação contra a Covid-19. Aplicou-se o instrumento de medição do Índice de Transparência da Vacinação contra a Covid-19 (ITVC-19) em seis levantamentos semanais, entre os meses de abril e junho, para verificar como o índice se distribuiu ao longo do país, bem como identificar possíveis evoluções na transparência da vacinação no decorrer dos levantamentos efetuados. Observou-se a constância de alguns estados em níveis superiores e inferiores (ou seja, nos extremos), e evolução de outros, saindo de níveis inferiores para níveis superiores. Grosso modo, embora a grande maioria dos portais eletrônicos dos estados brasileiros, objeto empírico da pesquisa, contribuam para a transparência da vacinação contra a Covid-19, há estados cujo portais, por se situarem em níveis opaco, baixo e médio, parecem existir mais em razão de um imperativo tecnológico dominante e menos para favorecer a transparência das ações governamentais.

Mesmo identificando uma condição satisfatória em parcela representativa dos entes investigados, faltam informações sobre o processo de vacinação, bem como são necessários vários cliques para se obter a informação, muitas vezes pulverizada em painéis, boletins epidemiológicos e notícias. De forma particular, o critério sexo foi um dos itens menos atendidos, mesmo o Plano Nacional de Operacionalização da Vacinação contra a Covid-19 (Lei n. ${ }^{\circ}$ 13.979, 2020) definindo que tal dado seria colocado à disposição do público em geral. Chamou atenção também o fato de que a maioria das informações que constavam em painéis, boletins epidemiológicos e notícias não eram concomitantemente disponibilizadas em formato aberto. Tais constatações, inclusive, remetem à necessidade de revisão do próprio modelo de análise.

A identificação de uma condição satisfatória em muitos estados brasileiros não significa que não se está diante de um longo caminho de avanços a ser percorrido. Mesmo alguns estados identificados com nível alto de transparência ainda podem evoluir, esforço este que tende a ser maior nos estados que ocupam os níveis inferiores (baixo e opaco). $\mathrm{O}$ avanço na construção de uma transparência sobre a vacinação, não só em relação à Covid-19, mas no sentido geral das vacinas, é importante para informar o cidadão, mas também enquanto elemento de gestão de políticas públicas. 
Assim, observa-se que o estudo contribui em termos teóricos e práticos. A contribuição teórica fica por conta de um campo extremamente incipiente quando o foco é a transparência do processo da vacinação. Ainda que o índice da OKBR contemple atualmente critérios relacionados à vacinação, à época em que o ITVC-BR foi construído e os dados foram coletados, não foram encontrados índices que proporcionassem estas análises. Portanto, tem o estudo uma implicação teórica direta quando proporciona o desenvolvimento de um índice que contribui para a análise da transparência no processo de vacinação contra a Covid-19. Pressupõe-se que o índice, futuramente, poderá ser utilizado também para outros tipos de vacinação, e não apenas este restrito ao contexto pandêmico. Consequentemente, contribui com o gap na literatura, notadamente nacional, captado por meio de levantamento na base de dados Spell.

Quanto ao foco prático, o estudo já demonstrou contribuições aos estados durante o próprio desenvolvimento da pesquisa, já que após o fechamento de cada levantamento foram os resultados encaminhados aos respectivos setores de comunicação para que pudessem não só fazer a conferência e indicar alguma incoerência na coleta, se fosse o caso, mas também verificar pontos a serem aperfeiçoados na transparência do processo de vacinação. A contribuição prática também é demonstrada por meio de um diagnóstico que poderá ser utilizado pelos gestores públicos, além da constatação de que a transparência na vacinação é apenas um dos muitos segmentos/olhares da transparência que merece atenção, representando um campo vasto e fértil em termos de pesquisa.

Estudos futuros são encorajados para que possam dar continuidade à temática aqui empregada. Inicialmente são vislumbradas pesquisas que prossigam com as coletas nos portais dos estados, tendo a intenção de verificar possíveis evoluções na transparência da vacinação. Outros estudos podem ser realizados com regiões metropolitanas ou municípios. Estudos paralelos podem ser conduzidos aperfeiçoando o modelo de análise. Na perspectiva da Ciência Contábil, pesquisas poderão ser realizadas com o foco de verificar como a Contabilidade Pública pode contribuir para aperfeiçoar a evidenciação dos resultados obtidos com a implementação de políticas públicas direcionadas para questões epidemiológicas/sanitárias.

\section{REFERÊNCIAS}

Decreto $n .^{\circ} 8.777$, de 11 de maio de 2016 (2016). Institui a Política de Dados Abertos do Poder Executivo Federal. Diário Oficial da União. Brasília, DF.

Lei Complementar $n .^{\circ}$ 101, de 04 de maio de 2000 (2000). Estabelece normas de finanças públicas voltadas para a responsabilidade na gestão fiscal e dá outras providências. Diário Oficial da União. Brasília, DF.

Lei Complementar n. ${ }^{\circ}$ 131, de 27 de maio de 2009 (2009). Acrescenta dispositivos à Lei Complementar n. ${ }^{\circ} 101$, de 4 de maio de 2000, que estabelece normas de finanças públicas voltadas para a responsabilidade na gestão fiscal e dá outras providências, a fim de determinar a disponibilização, em tempo real, de informações pormenorizadas sobre a execução orçamentária e financeira da União, dos Estados, do Distrito Federal e dos Municípios. Diário Oficial da União. Brasília, DF.

Lei $n .^{\circ} 12.527$, de 18 de novembro de 2011 (2011). Regula o acesso a informações previsto no inciso XXXIII do art. $5^{\circ}$, no inciso II do $\S 3^{\circ}$ do art. 37 e no $\S 2^{\circ}$ do art. 216 da Constituição Federal; altera a Lei n. ${ }^{\circ} 8.112$, de 11 de dezembro de 1990; revoga a Lei n. ${ }^{\circ} 11.111$, de 5 de maio de 2005, e dispositivos da Lei n. ${ }^{\circ} 8.159$, de 8 de janeiro de 1991; e dá outras providências. Diário Oficial da União. Brasília, DF. 
Lei $n^{\circ} 13.979$, de 06 de fevereiro de 2020 (2020). Dispõe sobre as medidas para enfrentamento da emergência de saúde pública de importância internacional decorrente do coronavírus responsável pelo surto de 2019. Diário Oficial da União. Brasília, DF.

Loureiro, M. R., Teixeira, M. A. C., \& Prado, O. (2008). Construção de instituições democráticas no Brasil contemporâneo: transparência das contas públicas. Organizações \& Sociedade, 15(47), 107-119.

Machado, L. N. et al. (2020). Restrições ao direito de acesso à informação em contextos emergenciais: análise dos efeitos da Covid-19 nos governos subnacionais. Revista da CGU, 12(22), 246-259.

Michener, G., Contreras, E., \& Niskier, I. (2018). Da opacidade à transparência? avaliando a lei de acesso à informação no Brasil cinco anos depois. Revista de Administração Pública, 52(4), 610-629.

Open Knowledge Brasil. (2020). Índice de Transparência da Covid-19: nota metodológica. $\begin{array}{lllll}\text { Recuperado em } & 02 & \text { maio, }\end{array}$ https://transparenciacovid19.ok.org.br/files/Nota_Metodologica_Transparencia_da_Covid19_2.0.pdf

Pinho, J. A. G., \& Sacramento, A. R. S. (2009). Accountability: já podemos traduzi-la para o português? Revista de Administração Pública, 43(6), 1343-1368.

Pinho, J. A. G. et al. (2020). Transparência governamental em capitais dos estados no Brasil nas contratações emergenciais para o combate da Covid-19. Revista da CGU, 12(22), 260-274.

Portaria GM/MS n. ${ }^{\circ}$ 69, de 14 de janeiro de 2021 (2021). Institui a obrigatoriedade de registro de aplicação de vacinas contra a Covid-19 nos sistemas de informação do Ministério da Saúde. Diário Oficial da União. Brasília, DF.

Raupp, F. M., \& Pinho, J. A. G. (2020). Precisamos evoluir em transparência? - uma análise dos estados brasileiros na divulgação de informações sobre a Covid-19. Gestão e Sociedade, 14(39), 3725-3739.

Raupp, F. M., \& Pinho, J. A. G. (2021). Websites dos Poderes Executivos Estaduais e as Contratações Emergenciais em Meio à Pandemia da Covid-19: Há Tecnologia, mas Falta Transparência. Revista Gestão Organizacional, 14(1), 416-428.

Raupp, F. M., Sacramento, A. R. S., Santos, R. C. N., \& Pinho, J. A. G. de. (2021). Índice de transparência da vacinação contra a Covid-19 no Brasil: um estudo à luz da realidade empírica das capitais brasileiras. Teoria e Prática em Administração, 11(especial em saúde), 1-16.

Sacramento, A. R. S., \& Pinho, J. A. G. de. (2016). O processo de implementação da answerability no Brasil contemporâneo. Revista de Administração Pública, 50(2), 193-213.

Santos, J. G. D., \& Mota, F. P. B. (2020). A transparência governamental em tempos de Covid19: reflexões do quadro brasileiro. Gestão e Sociedade, 14(39), 3716-3724. 
Schedler, A. (1999). Conceptualizing accountability. In A. Schedler, L. Diamond, \& M. F. Plattner (Eds). The self-restraing state: power and accountability in new democracies. Boulder and London: Lynne Rienner Publishers, 13-28.

Zuccolotto, R., Teixeira, M. A. C., \& Riccio, E. L. (2015). Transparência: reposicionando o debate. Revista Contemporânea de Contabilidade, 12(25), 137-158. 